\title{
Profile of Pediatric Poisoning at District Hospital Gulbarga
}

\author{
Shashidhar $\mathbf{V}^{1}$, Yogesh $\mathbf{G}^{2}$ \\ ${ }^{1}$ Dr Shashidhar Veerappa, Assistant Professor, Department of Pediatrics, ${ }^{2}$ Dr Yogesh G, Senior Resident. Both affiliated with \\ E. S. I. Medical College, Gulbarga, Karnataka, India
}

Address for Correspondence: Dr Shashidhar Veerappa, Email: docnandi@gmail.com

\begin{abstract}
Introduction: Children are curious and explore their world with all their senses, including taste. As a result, the home and its surroundings can be a dangerous place when poisonous substances are inadvertently ingested. Methods: This study was done to know the profile of poisoning cases in pediatric age group in district hospital Gulbarga. It is a retrospective study of Pediatric poisoning between August 2011 and July 2013. Results: Poisoning constituted 0.73\% of all Pediatric admissions. Distribution of cases among boys and girls were equal. Majority (68\%) of these cases were from rural areas. Only one case of poisoning happened by inhalation / dermal absorption during farming activity, rest 36 (97\%) were by oral ingestion. Most (81\%) of these poisoning happened in the home environment. Out of the 7 (19\%) outdoor poisoning 6 were plant poisons, which were eaten out of curiosity by children. Pesticide was the most common poison found in the study followed by lice powder and kerosene. Nonspecific gastrointestinal complaints like vomiting (75.7\%), pain abdomen (40.5\%) and loose stools $(21.6 \%)$ were the most common symptoms with which children with poisoning presented to hospital. Conclusions: Poisoning in children remains one of the causes of emergency admissions to hospital. It is target population regarding proper storage of potential poisonous substances away from the reach of children.
\end{abstract}

Keywords: Pediatric Poisoning, District Hospital, Retrospective Study

\section{Introduction}

Children are curious and explore their world with all their senses, including taste. As a result, the home and its surroundings can be a dangerous place when poisonous substances are inadvertently ingested ${ }^{1}$. Acute poisoning in children is a major preventable cause of morbidity and mortality.

It is a world-wide problem although the nature of poison consumed may vary in developed and underdeveloped countries due to variable accessibility. In 2004, acute poisoning caused more than 45,000 deaths in children and youth under 20 years of age $-13 \%$ of all fatal accidental poisonings worldwide.

The rate of fatal poisoning is highest for children under one year, with another slight peak around 15 years. Fatal poisoning rates in low-income and middle-income countries are four times that of high-income countries. ${ }^{1}$

This study was done to know the profile of poisoning cases in pediatric age

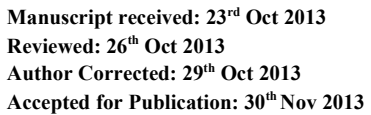

group in district hospital Gulbarga. It is a 500 bedded hospital and part of Karnataka state health department. It caters to the people of Gulbarga city and surrounding areas.

\section{Materials and methods}

We retrospectively reviewed the hospital records of all the paediatric patients who presented with acute poisoning during the 2-years period from August 2011 to July 2011. We profiled all cases of paediatric poisoning and noted their outcome. All children and adolescents aged up to 18 years with a definite history of poisoning were included.

Children who had food poisoning, reaction to prescribed drugs, snake bites and scorpion stings were excluded from the study. Data regarding age, sex, type and quantity of substance consumed, time of ingestion, time of symptom onset, time of presentation to hospital, relevant social factors, symptoms and signs, investigations, therapeutic interventions, and outcome was noted on a predesigned proforma. Since it was a retrospective study, ethical clearance was not required. References have been listed according to Vancouver style. 


\section{Results}

During the study period from August 2011 to July 2013, a total of 78 children were admitted with the clinical diagnosis of acute poisoning. This constituted $1.54 \%$ of the total 5063 admissions to the Paediatric ward. Among these 78 cases, 41 were excluded from the study as they constituted food poisoning (25cases), snake bite (12cases), unknown insect bite (2cases), scorpion sting (1case) and drug reaction (1 case). Of the remaining 37 cases which constituted $0.73 \%$ of the total Paediatric admissions, 18 were girls and 19 were boys (M: F=1:1). Majority of these cases were from rural areas, 25(68\%) cases as compared to $15(32 \%)$ cases from urban area. Only one case of poisoning happened by inhalation / dermal absorption during farming activity, rest 36 (97\%) were by oral ingestion. Most (81\%) of these poisoning happened in the home environment. Out of the 7 (19\%) outdoor poisoning 6 were plant poisons, which were eaten out of curiosity by children

Table1: Distribution of Cases according to age and type of poisoning

\begin{tabular}{|l|l|l|l|l|l|}
\hline Age & Accidental & Suicidal & Homicidal & Male :Female & Total \\
\hline$<$ 6yrs & 14 & 0 & 0 & $9: 5$ & 14 \\
\hline 6-12yrs & 9 & 5 & 1 & $8: 7$ & 15 \\
\hline $\mathbf{1 3 - 1 8 y r s}$ & 0 & 8 & 0 & $2: 6$ & 8 \\
\hline Total & 23 & 13 & 1 & $19: 18$ & 37 \\
\hline
\end{tabular}

The distribution of cases according to age and type of poisoning is shown in Table 1. Cases in the age group of under 6 yrs and $6-12$ yrs were $38 \%$ and $40 \%$ respectively. The remaining $22 \%$ were in the age group of $13-18$ yrs. Boys were significantly more in under 6yrs age group $(\mathrm{M}: \mathrm{F}=64 \%: 36 \%)$, whereas girls were more commonly affected in 13-18yrs age group(M:F=25\%:75\%). Distribution among both sexes was equal in 6-12yrs age group. There was a case of a child being intentionally poisoned by mother due to domestic problem.

Table 2: Toxic agents involved according to mode of poisoning

\begin{tabular}{|c|c|c|c|c|}
\hline Poison & Accidental & Suicidal & Homicidal & Total \\
\hline Pesticide & 6 & 4 & 1 & $11(30 \%)$ \\
\hline Lice Powder & 2 & 6 & 0 & $8 \quad(21 \%)$ \\
\hline Kerosene & 7 & 0 & 0 & $7 \quad(19 \%)$ \\
\hline Wild Fruits & 5 & 0 & 0 & $5 \quad(14 \%)$ \\
\hline Mushroom & 1 & 0 & 0 & $1 \quad(2.5 \%)$ \\
\hline Phenyl & 1 & 0 & 0 & $1 \quad(2.5 \%)$ \\
\hline Turpentine & 1 & 0 & 0 & $1 \quad(2.5 \%)$ \\
\hline Paracetamol & 0 & 1 & 0 & $1 \quad(2.5 \%)$ \\
\hline Tablet Chlorpromazine & 0 & 1 & 0 & $1 \quad(2.5 \%)$ \\
\hline Unknown Tablet & 0 & 1 & 0 & $1 \quad(2.5 \%)$ \\
\hline Total & 23 & 13 & 1 & 37 \\
\hline
\end{tabular}

Table 2 shows the toxic agents involved in this study according to the mode of presentation. Pesticide was the most common poison found in our study. Pesticide along with lice powder constituted half of the cases. Kerosene was the third most common agent in our study and all of them were accidental poisoning in children less than $3 y r s$. There were 6 cases of accidental plant poisoning admitted during this period, all of them happened in outdoor environment. Three cases of drug poisoning were admitted, all with intentions of deliberate self harm. 
Table 3: Symptoms in patients with poisoning

\begin{tabular}{|l|l|l|}
\hline Symptom & No of Patients & Percentage \\
\hline Vomiting & 28 & $75.7 \%$ \\
\hline Pain Abdomen & 15 & $40.5 \%$ \\
\hline Diarrhea & 8 & $21.6 \%$ \\
\hline Cough & 6 & $16.2 \%$ \\
\hline Giddiness & 5 & $13.5 \%$ \\
\hline Sweating & 5 & $13.5 \%$ \\
\hline Fever & 4 & $10.8 \%$ \\
\hline No Symptoms & 3 & $8.1 \%$ \\
\hline Blurring of Vision & 2 & $5.4 \%$ \\
\hline Fast Breathing & 2 & $5.4 \%$ \\
\hline Drowsiness & 2 & $5.4 \%$ \\
\hline Drooling of oral secretions & 1 & $2.7 \%$ \\
\hline
\end{tabular}

Table 3 shows the common symptoms with which the patients presented to hospital. Vomiting was the most common symptom followed by pain abdomen, diarrhea, sweating, giddiness, cough and fever. Three children were brought without any symptoms following incidents of poisoning. Two children complained of blurring of vision in pesticide poisoning. Drooling of oral secretions was seen in a case of phenyl poisoning.

Fig 1: Distribution of patients according to month of presentation

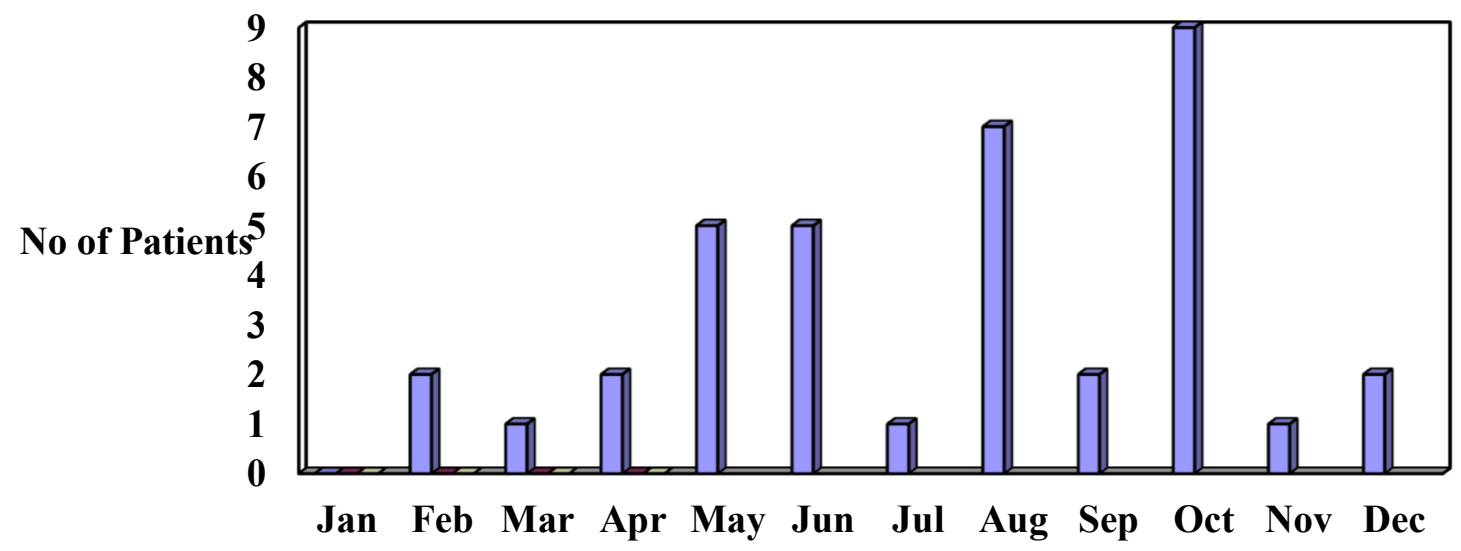

Fig1. Shows distribution of patients according to the month of presentation. October month had the highest number of admissions of poisoning cases followed August, May and June. There were no cases of poisoning admitted in January month during the study period

\section{Discussion}

Poisoning remains one of the causes of emergency admission in paediatric age group. This study was done to know the profile of children admitted with poisoning to pediatric department. Identifying epidemiology aspects in childhood poisoning will be of great importance for planning treatment and for determination of proper preventive measures. The incidence of poisoning in our study was $0.73 \%$ of the total pediatric admissions in this hospital. The reported incidence of poisoning in India varies from $0.33 \%$ to $7.6 \%{ }^{2}$

The distribution of cases among boys and girls in this study was almost equal (M: $\mathrm{F}=51 \%: 49 \%$ ). However in the 
under six age group number of boys were almost double to girls $(\mathrm{M}: \mathrm{F}=64 \%: 36 \%$ ), were as in $13-18 \mathrm{yrs}$ age group girls were three times the number of boys $(\mathrm{M}: \mathrm{F}=$ 25\%:75\%). Most of the studies done in India have shown a male preponderance of poisoning cases among children..$^{3-7}$ All of these studies have included children below $15 y$ rs only. The reason for having equal incidence in the present study could be because of inclusion of adolescent children. Equal distribution of both sexes was also found in the study done by Shivani et al, where children up to 17 yrs were included. ${ }^{8}$

Most $(25,68 \%)$ of the cases in this study were from rural areas. However the studies done in big cities in India have shown a preponderance of cases coming from urban area. $^{3-5,7}$. This finding basically reflects the population profile to which the hospital caters to. Our hospital is a referral hospital for primary health centre and community health centre from Gulbarga district and adjacent Yadgir district. It also caters to lower and middle income population of Gulbarga city.

.Majority $(30,81 \%)$ of the poisonings in this study has happened in the indoor environment. Similar findings were reported in other studies. ${ }^{9}{ }^{10}$. Most of poison substance implicated in this study like pesticide and kerosene are normally present in the houses of farming based rural population. Improper storage of these substances and unattended children can give rise to accidental poisoning. Most of these accidental poisonings happen in children less than 6yrs of age who are curious and inquisitive about their surroundings and don't understand the consequence of mouthing them. Pesticide $(11,30 \%)$, Lice powder $(8,21 \%)$ and Kerosene (7, 19\%) were the common poisons found in our study. Plant poisons $(6,16.5 \%)$ and drugs $(3,7.5 \%)$ were next common. Pesticides and Kerosene are the common poisons being reported in all studies done in India, however the percentage of cases varies from place to place. $^{3-} 5,11$. These were also the common poisons in a study done in Katmandu, Nepal ${ }^{12}$. The profile of poisons was different in studies published from developed countries. Drugs were the most common followed by household chemicals and personal care products. ${ }^{10,13-16}$. Studies done in Turkey and Iran have also reported a high incidence of poisoning with drugs, however corrosive substances and carbon monoxide were the next common poisons in their studies. ${ }^{9,17}$

Nonspecific gastrointestinal complaints like vomiting (75.7\%), pain abdomen (40.5\%) and loose stools (21.6\%) were the most common symptoms with which children with poisoning presented to hospital. Cough and breathlessness were reported in children with kerosene consumption. Blurring of vision was reported in two cases of pesticide poisoning. One child following accidental phenyl consumption had presented with drooling of saliva. Since most poisonings are by oral ingestion, gastrointestinal complaints predominate.

October had the highest incidence of poisoning admission with a quarter of all cases reported in this month. August (20\%) had the second highest incidence. There were no cases of poisoning admitted in the month of January. Studies which have included snake bites have shown a peak incidence during rainy season ${ }^{6}$.

Mortality in childhood poisoning in various studies done in India varies from 0 to $12.5 \% .^{2,3,5,7,11}$. There were no deaths due to poisoning during our study period. Majority of our cases were mild poisoning, most were discharged from hospital within 3 days. The longest stay was for 6 days in a case of pesticide poisoning.

\section{Conclusion}

Poisoning in children remains one of the causes of emergency admissions to hospital. Most of the cases were from rural areas involving pesticides and kerosene. Although no deaths were seen in this study, it is a potential cause of morbidity and mortality. Poisoning can be prevented by proper health education of target population regarding proper storage of potential poisonous substances away from the reach of children.

\section{Acknowledgements}

We would like to thank our Dean Dr M R Chandrashekar and District Surgeon Dr Nalini Namoshi for giving us permission to access hospital data and publish it.

\section{Funding: Nil}

Conflict of interest: Nil

Permission from IRB: Yes

\section{References}

1. WHO: world report on child injury prevention[Internet] 2008 [cited 2013 Sept] Available at: http://www.who.int/violence_injury_prevention/child/en/ http://www.who.int/violence_injury_prevention/child/en/h http://www.who.int/violence_injury_pre

2. Dutta AK, Seth A, Goyal PK, Aggarwal V, Mittal SK, Sharma R, Bahl L, Thakur JS, Verma M, Chhatwal J, Chacko B, Saini V, Singhal A, Sharma P, Sharma U,Chaturvedi P, Kumar S, Prajapati NC, Vaidya J, Garg N, Basu SN, Lahiri M, Das CK, Pal DK, Lall SB. Poisoning in children: Indian scenario. Indian $\mathrm{J}$ Pediatr. 1998; 65(3): 365-70. 
3. Kohli U, KuttiatVS, Lodha R, Kabra SK. Profile of childhood poisoning at a tertiary care centre in north India. Indian J Pediatr 2008; 75(8):791-94.

4. Singh S, Singhi S, Sood NK, Latakumar, Walia BNS. Changing pattern of childhood poisoning (1979-1989): Experience of a large north Indian hospital. Indian Pediatr.1995; 32(3):331-36

5. Gupta S, Govil YC, Misra PK, Nath R, Srivastava KL.Trends in poisoning in children: experience at a large referral teaching hospital. The National Medical Journal of India 1998; 11(4):166-168

6. Kumar V. Accidental poisoning in south west maharastra. Indian Pediatr. 1991; 28(7):731-5

7. Rathore S, Verma AK, Pandey A, Kumar S. Pediatric poisoning trend in Lucknow District. J Forensic Res[Internet]. 2013; 4(1): 179. Available from: http://dx.doi.org/10.4172/2157-7145.1000179

8. Shivani R, Neelam G, Rakesh S, Hemanth S. Acute poisoning in children: seven year experience at a tertiary care hospital of north India. Curr Pediatr Res 2011; 15(1): $65-68$

9. Nesibe A, Fikriye S. Pattern of acute poisonings in childhood in Ankara: what has changed in twenty years. Turk J Pediatr 2004; 46(2): 147-52

10. Azkunaga B, Mintegi S, Salmon N, Acedo Y, DelAcro L. Poisoning in children under age 7 in spain.
Areas iof improvement in the prevention and treatment. An Pediatr 2013; 78(6) :355-60

11. Jayashree M, Singhi S. Changing trends and predictions of outcome in patients with acute poisoning admitted to the intensive care. J Trop Pediatr 2011; 57(5): $340-46$

12. Chhetri UD, Ansari I, Shrestha S. Pattern of pediatric poisoning and accident in Patan Hospital. Kathmandu Univ Med J (KUMJ). 2012 ;10(39):39-43.

13. Franklin RL, Rodgers GB. Unintentional child poisonings treated in United States hospital emergency departments: national estimates of incident cases, population based poisoning rates and product involvement. Pediatrics 2008; 122(6):1244-51

14. Neilson ZE, Morrison W. Childhood self poisoning: a one year review. Scott Med J 2012; 57(4): 196-99

15. Spiller AH, Beuhler MC, Ryan ML, Borys DJ, Alequas A, Bosse GM. Evaluation of changes in poisoning in young children: 2000 to 2010. Pediatr Emerg Care. 2013; 29(5): 635-40

16. Hoikka MH, Liisanantti JH, Dunder T. Acute poisoning in children under the age of six: a two-decade study of hospital admissions and trends. Acta Pediatr 2013; 102(7): 329-33

17. Sabiha S, Kursat BC, Ener CD. Acute poisoning in children: Data of a paediatric emergency unit. Iran J Pediatr. 2011; 21(4): 479-84.

\section{How to cite this article?}

Shashidhar V, Yogesh G. Profile of Pediatric Poisoning at District Hospital Gulbarga. Int J Med Res Rev 2013;1(5):245-249. doi:10.17511/ijmrr.2013.i5.06. 